\section{Nonstationary gravity wave forcing of the stratospheric zonal mean wind}

\author{
M. J. Alexander \\ Department of Atmospheric Sciences, University of Washington, Seattle
}

\author{
K. H. Rosenlof \\ Cooperative Institute for Research in Environmental Science, University of Colorado, Boulder \\ National Oceanic and Atmospheric Administration, Boulder, Colorado
}
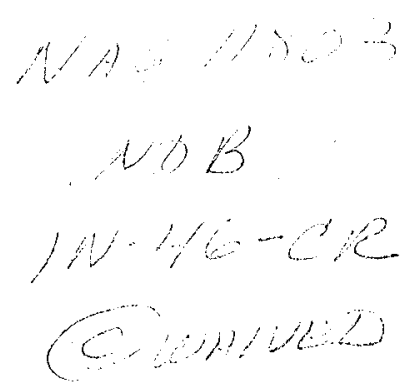

\begin{abstract}
The role of gravity wave forcing in the zonal mean circulation of the stratosphere is discussed. Starting from some very simple assumptions about the momentum flux spectrum of nonstationary (non-zero phase speed) waves at forcing levels in the troposphere, a linear model is used to calculate wave propagation through climatological zonal mean winds at solstice seasons. As the wave amplitudes exceed their stable limits, a saturation criterion is imposed to account for nonlinear wave breakdown effects, and the resulting vertical gradient in the wave momentum flux is then used to estimate the mean flow forcing per unit mass. Evidence from global, assimilated data sets are used to constrain these forcing estimates. The results suggest the gravity-wave-driven force is accelerative (has the same sign as the mean wind) throughout most of the stratosphere above $20 \mathrm{~km}$. The sense of the gravity wave forcing in the stratosphere is thus opposite to that in the mesosphere, where gravity wave drag is widely believed to play a principal role in decelerating the mesospheric jets. The forcing estimates are further compared to existing gravity wave parameterizations for the same climatological zonal mean conditions. Substantial disagreement is evident in the stratosphere, and we discuss the reasons for the disagreement. The results suggest limits on typical gravity wave amplitudes near source levels in the troposphere at solstice seasons. The gravity wave forcing in the stratosphere appears to have a substantial effect on lower stratospheric temperatures during southern hemisphere summer and thus may be relevant to climate.
\end{abstract}

\section{Introduction}

Gravity wave forcing plays an important role in determining the circulation and temperature structure of the mesosphere. Leovy [1964] established the existence of a missing zonal force in the mesosphere that drives this region of the atmosphere far from the radiative equilibrium solution to the temperature and wind structure. He parameterized this force as Rayleigh friction, which slowed the zonal winds and drove a meridional circulation whose associated diabatic effects cause the unseasonal cold summer pole and warm winter pole at the mesopause. The development of a parameterization for gravity wave forcing by Lindzen [1981] and its adaptation by Holton [1982, 1983] demonstrated that gravity wave breaking could supply this missing force in the mesosphere.

Subsequent studies have confirmed and expanded the potential role of gravity wave effects on the middle atmosphere. The turbulent mixing associated with gravity wave breaking has been shown to affect the composition of the mesosphere and lower thermosphere [Garcia and Solomon, 1985]. Gravity wave forcing is an important component in driving the equatorial semiannual oscillation at the mesopause [Dunkerton, 1982; Hamilton and Mahlman, 1988; Jackson and Gray, 1994]. Mesospheric

Copyright 1996 by the American Geophysical Union.

Paper number 96JD02197.

0148-0227/96/96JD-02197\$09.00 gravity wave drag can affect the state of the polar winter upper stratosphere [Hitchman et al., 1989; Garcia and Boville, 1994], consistent with the downward control principle [Haynes et al., 1991]. The filtering of gravity waves during sudden stratospheric warmings is believed to be responsible for the associated mesospheric coolings [Holton, 1983; Huang and Smith, 1995]. Orographically excited gravity wave drag in the lower stratosphere is believed to be important to general circulation of the troposphere and lower stratosphere [Palmer et al., 1986; McFarlane, 1987; Bacmeister, 1993].

In the extratropical mesosphere, the zonal mean gravity wave force must be decelerative in order to explain the observed latitudinal temperature gradient and zonal winds at solstice seasons. By using the term "decelerative," we mean the sign of the force is opposite to the zonal mean wind. The magnitude of this gravitywave-driven force has been inferred to peak at $\sim 100 \mathrm{~m} \mathrm{~s}^{-1} \mathrm{~d}^{-1}$ [e.g., Holton, 1983; Fritts and Vincent, 1987; Fritts and Yuan, 1989]. Middle-atmosphere models employing the Lindzen [1981] parameterization with nonstationary (non-zero phase speed) gravity waves often produce a gravity-wave-driven decelerative force that extends deeply into the stratosphere as well, although in the stratosphere, the magnitude of the force is weak compared with the mesosphere [e.g., Garcia and Solomon, 1985; Brasseur et al., 1990]. Observational evidence, however, has poorly constrained the gravity-wave-induced force in the middle and upper stratosphere. Both its magnitude and sign are uncertain. In winter seasons, planetary-scale wave forcing dominates the momentum budget in the stratosphere. Rosenlof [1996], how- 
ever, suggests gravity wave forcing may be important in determining lower stratospheric temperatures during the summer seasons. Her results employed the downward control principle [Haynes et al., 1991] to suggest a downward mass flux in the lower stratosphere due to small-scale wave forcing in the extratropical summer hemisphere. This downward summer flux is consistent with an accelerative small-scale zonal force (the force has the same sign as the zonal wind) in the middle and upper stratosphere. This is a westward force in the summer stratosphere, opposite to the sense of the mesospheric gravity wave force and opposite to the sense of the stratospheric gravity wave force in the models described above.

In this work, we demonstrate the potential role of nonstationary gravity waves in providing this extratropical accelerative zonal force in the middle and upper stratosphere. A linear ray-tracing model with saturation, previously described by Alexander [1996], is employed to estimate the zonal gravitywave-induced force from a broad spectrum of waves originating in the troposphere. The constraining evidence in the mesosphere coupled to Rosenlof's [1996] constraints at lower levels are together shown to have implications for the amplitudes of gravity waves at source levels in the troposphere. The total momentum flux carried by a given source spectrum of waves is also constrained by this method, although the uncertainties in the spectral shape still allow a wide range of possible flux values.

\section{Observational Constraints}

Using global measurements of temperature, wind, and chemical constituents, an estimate can be made of the zonal mean zonal forcing associated with unresolved waves in the stratosphere. This is done by first estimating the residual or diabatic circulation $\left(\bar{v}^{*}, \bar{w}^{*}\right)$ from the transformed Eulerian mean equations [Andrews et al., 1987, pp. 128-129]. An iterative solution of the thermodynamic energy and continuity equations is obtained with heating rates determined from a radiative transfer model as described by Rosenlof [1995]. The solution for $\left(\bar{v}^{*}, \bar{w}^{*}\right)$ and the wind derivatives estimated from the global measurements can then be used to evaluate the right-hand side of the zonally averaged momentum equation,

$$
\begin{gathered}
\frac{\partial \bar{u}}{\partial t}+\bar{v}^{*}\left[\frac{1}{a \cos \phi} \frac{\partial}{\partial \phi}(\bar{u} \cos \phi)-f\right]+\bar{w}^{*} \frac{\partial \bar{u}}{\partial z} \\
=\frac{1}{\rho_{0} a \cos \phi} \nabla \cdot F+\bar{X},
\end{gathered}
$$

which will give the total zonal momentum force consisting of contributions from both the Eliassen-Palm (EP) flux divergence $\nabla \cdot F$ [see Edmon et al., 1980] and any unresolved zonal forces $\bar{X}$. All other symbols follow the definitions given by Andrews et al. [1987]. This method was used by Shine [1989] to estimate total momentum forcing in the upper stratosphere and mesosphere. In that paper, he also discusses uncertainties with the resultant estimate. Subtracting the resolved forcing

$$
\frac{1}{\rho_{0} a \cos \phi} \nabla \cdot F
$$

from the total zonal momentum forcing gives an estimate for the forcing attributable to the unresolved waves. Similar attempts to infer the small-scale forcing are made by Hartmann [1976],
Hamilton [1983], and Smith and Lyjak [1985]. These authors each focused on a single hemisphere and season: southern winter, northern winter, and late northern fall-winter, respectively.

For this study, the total zonal momentum forcing was estimated from a heating rate calculation [Rosenlof, 1995] which uses Upper Atmosphere Research Satellite (UARS) constituents and temperatures as input. The momentum forcing due to resolvable scales was estimated from the National Meteorological Center (NMC) stratospheric analysis and from the United Kingdom Meteorological Office (UKMO) assimilated data. The NMC estimate includes contributions due to scales up to zonal wavenumber 12. The UKMO encompasses scales up to zonal wavenumber 48 . The total zonal forcings derived by this method for January and July were shown in Rosenlof [1995]. December and June maps are similar to January and July, respectively, but with a more uniform westward forcing in the summer hemispheres. The necessity of a modest westward force in the summer stratosphere is apparent in models which relax to radiative equilibrium poleward of the subtropics [Dunkerton, 1989, 1996]. Without this westward body force, tropospheric jets close at unrealistically high altitude (T. Dunkerton, personal communication, 1996).

The unresolved portion of the forcing, shown in Figures 1a-1d, represents the zonal mean zonal forcing due to synoptic-scale and gravity waves. Significant differences between NMC and UKMO occur in the winter hemispheres, where lots of latitudinal structure appears. Some of these differences could be due to differences in their resolution. In the summer hemispheres, however, the NMC and UKMO estimates are very similar and also do not vary much from year to year (not shown). It is difficult to estimate the uncertainty in these maps, though the EP-flux divergence is likely to be the most uncertain portion of the calculation, and it is in the winter seasons that this term is largest. Equatorial latitudes are omitted because the balance equations used to derive the NMC winds tend to diverge there [Randel, 1992]. (The UKMO assimilation does not suffer this problem; however, the minimal amount of data that actually goes into the data assimilation in the tropics likely results in poor estimates there, and our focus here is on the extratropical latitudes where Rosenlof's [1996] analysis applies.) In summer seasons, the unresolved component of the wave-driven forcing (like the total forcing) is westward and represents a significant fraction of the total. Rosenlof [1996] suggests that small-scale, wavedriven forces affect a significant $2.5-5^{\circ} \mathrm{K}$ temperature asymmetry between the southern and northern hemisphere lower stratospheres by enhancing the downward mass flux and that this temperature difference is observed in Microwave Sounding Unit [Spencer et al., 1990] data. The unresolved forcing represents the majority of the total forcing at midlatitudes above $\sim 30-40 \mathrm{hPa}$, while resolved waves play a more significant role in the stratosphere below that level. We now examine the potential role of nonstationary gravity waves in supplying this small-scale forcing.

\section{Gravity Wave Forcing Estimates}

Nonstationary gravity wave sources are still poorly described by the observational evidence. Likely sources include convection and weather fronts in the troposphere and regions of shear instability in the jet stream. Here we make the simplest possible assumption that these sources are uniformly distributed in latitude with a broad spectrum of frequencies and phase speeds and with the same fractional coverages in space and time at each latitude. 

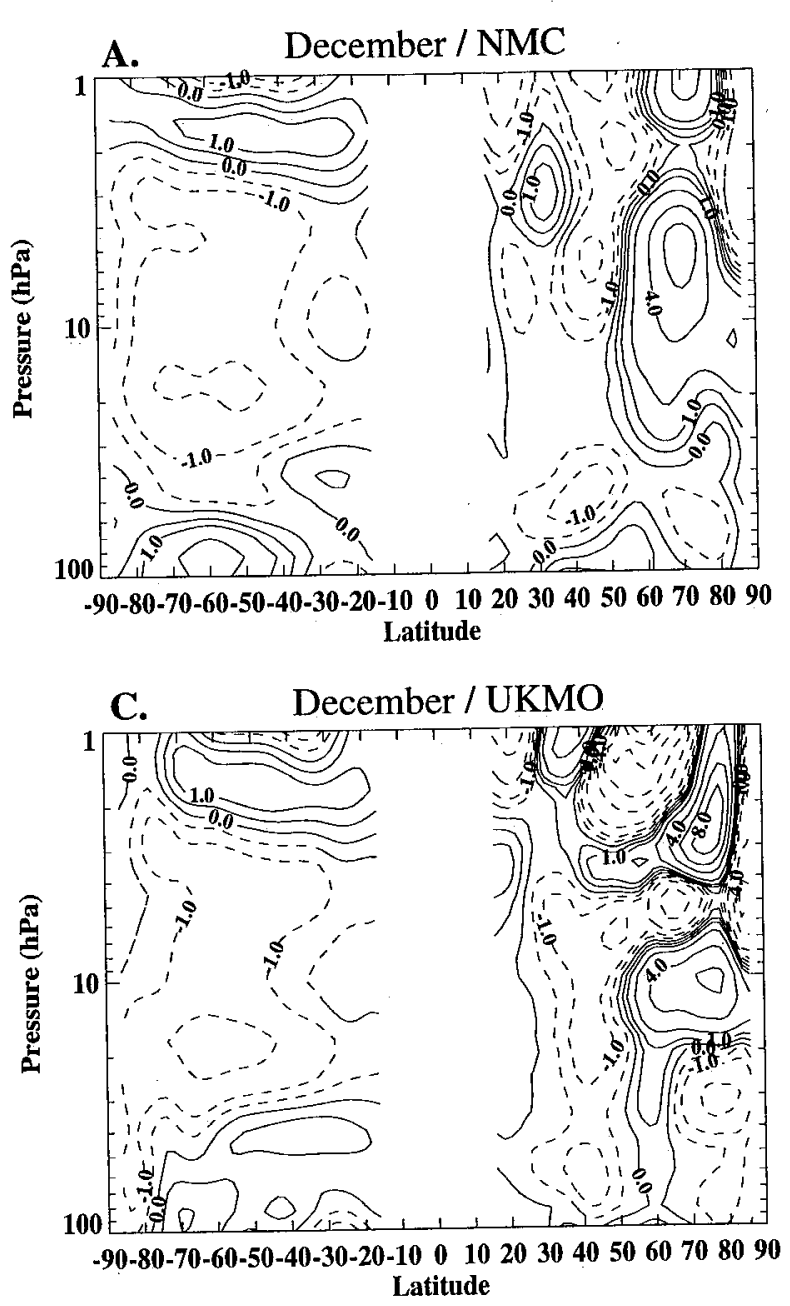
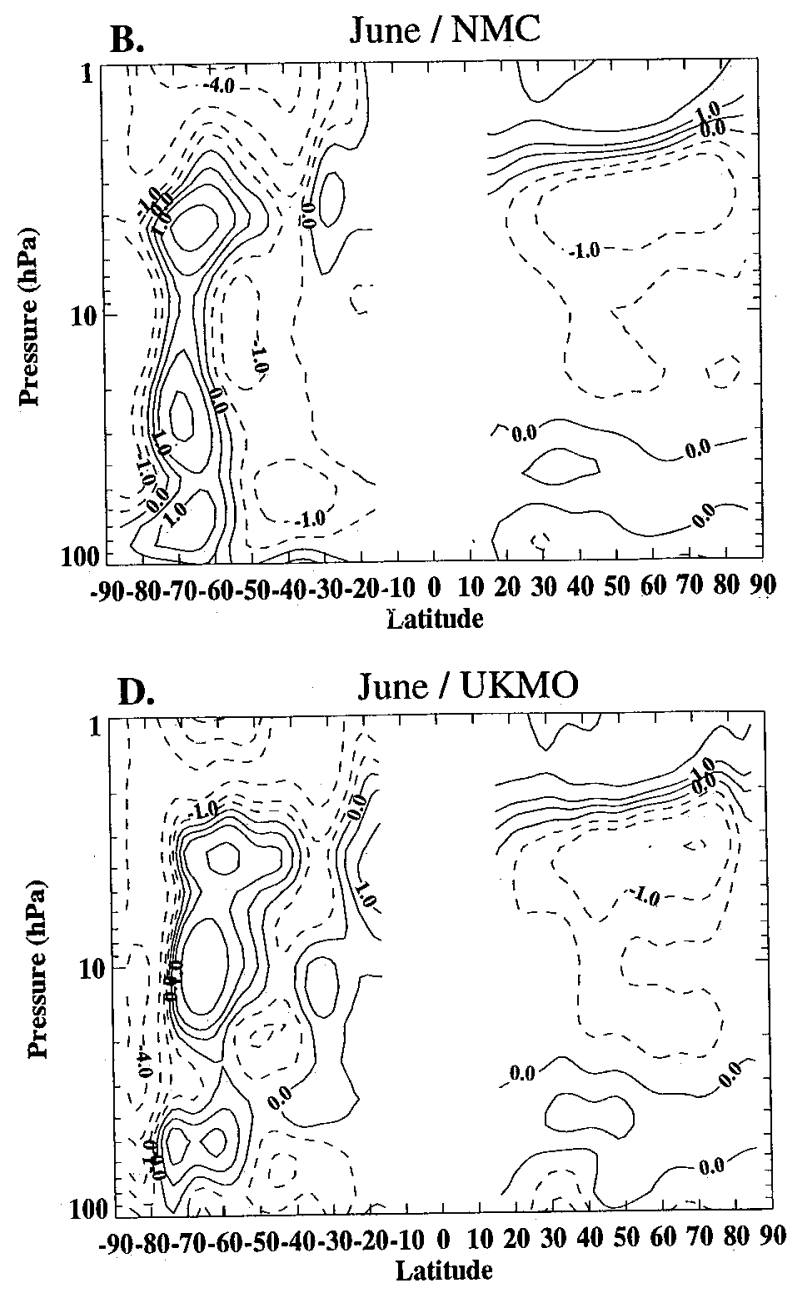

Figure 1. Small-scale forcing computed as the residual difference between the "total" and "resolved" forcing estimates. The total forcing is an estimate of the sum of both terms on the right-hand side of (1) (see text). The resolved forcing is the divergence of the Eliassen-Palm flux associated with resolved eddies in the National Meteorological Center data for (a) December and (b) June and United Kingdom Meteorological Office data for (c) December and (d) June. Contours are $0,0.5,1,2$, and $4 \mathrm{~m} \mathrm{~s}^{-1} \mathrm{~d}^{-1}$ and as marked. Dashed contours represent negative numbers. Residuals from both solstice seasons are shown. These are 2-year averages (1992-1993). Individual years look very similar during summer seasons. Consistent negative values in summer represent a smallscale accelerative force throughout most of the stratosphere.

These assumptions then isolate the effects of latitude/height variations in the zonal mean wind and stability on the gravity wave forcing estimates. Two existing gravity wave parameterizations will be compared to a more complex calculation using a linear model that realistically accounts for the physics of linear gravity wave propagation and treats the nonlinear effects of wave breaking with a saturation condition. This model is similar to the Lindzen [1981] parameterization, but it makes fewer simplifying assumptions.

\subsection{Linear Gravity Wave Model With Saturation (A96)}

We first apply the ray-tracing model described by Alexander [1996] to estimate the zonal mean gravity wave force. This model assumes linear propagation of a discrete gravity wave source spectrum and includes a discrete saturation condition applied when a given gravity wave's amplitude exceeds convective instability limits. The model is nonhydrostatic and has been modified here to include the effects of rotation in the gravity wave polarization and dispersion relations. Wave reflection can also occur when the wave is Doppler shifted to high intrinsic frequencies larger than the cutoff frequency. The cutoff frequency, assumed by Alexander [1996] to be the local buoyancy frequency $N$, has here been modified to include the density-scale height term as discussed by Marks and Eckermann [1995]. The new cutoff frequency tends to predict more wave reflection. It has little effect on the stratosphere but leads to decreases in the gravity-wave-driven forcing estimates in the mesosphere in the present calculations by up to $20 \%$. These changes to the Alexander [1996] (hereinafter referred to as A96) model let us examine a broader spectrum of waves than those associated with the convective source in that earlier work.

A gravity wave source spectrum must be specified. For each element of the spectrum the propagation properties of the wave must be specified (here we use intrinsic frequency and horizontal wavenumber), as well as the amplitude at the source altitude. The fractional coverage of each spectral element in longitude and time are additional variables. Alexander [1996] derived these 
from a wavelet analysis of a specific convective source. In applications of the Lindzen [1981] parameterization, by other researchers, these fractional converages were reduced to a single efficiency factor applied uniformly across the wave spectrum. Here we adopt the latter method because properties of gravity wave sources around the world are still poorly defined. The magnitude of the efficiency factor is constrained in this model by the midlatitude mesosphere gravity wave forcing, which is used as a calibration point for the zonal gravity wave force. The peak forcing in the upper mesosphere is here set to between 100 and $200 \mathrm{~m} \mathrm{~s}^{-1} \mathrm{~d}^{-1}$ in both hemispheres. This magnitude has been shown by previous authors to be sufficient to drive the residual meridional circulation and give the observed latitudinal temperature gradient in the upper mesosphere as described in the introduction. For a given gravity wave source spectrum, the model is first run using the CIRA reference atmosphere [Fleming et al., 1990] to specify background wind $\bar{U}$ and temperature $\bar{T}$ fields. These results set the value of the efficiency factor. The more realistic stratosphere $\bar{U}$ and $\bar{T}$ from the NMC analysis are subsequently used to derive the gravity-wave-driven force in the stratosphere using the same efficiency factor.

A variety of source spectra were examined to gauge the sensitivity of the model results to source characteristics. For the first series of calculations, it is assumed that each member of the gravity wave spectrum carries the same momentum flux. A flat momentum flux spectrum as a function of intrinsic frequency is observed in simulations of gravity waves above deep convection such as that of Alexander et al. [1995]. A spectrum with 60 discrete waves, isotropic in the east/west direction, was chosen with intrinsic periods ranging from $7 \mathrm{~min}$ to 4 hours, horizontal wavelengths from 6.25 to $800 \mathrm{~km}$, intrinsic phase speeds between +70 and $-70 \mathrm{~m} \mathrm{~s}^{-1}$ and vertical wavelengths from 1 to $25 \mathrm{~km}$. The total momentum flux in the source spectrum is $\pm 2.7 \times 10^{-3}$ $\mathrm{kg} \mathrm{m}^{-1} \mathrm{~s}^{-2}$ (including an efficiency factor of $3.0 \times 10^{-4}$ ). With this source specified in the middle troposphere at $6 \mathrm{~km}$, vertical velocity amplitudes are all $\leq 1 \mathrm{~m} \mathrm{~s}^{-1}$ at the source level.

The mesosphere results for June are shown in Figure 2. A seasonal asymmetry in the magnitude of the drag force in the

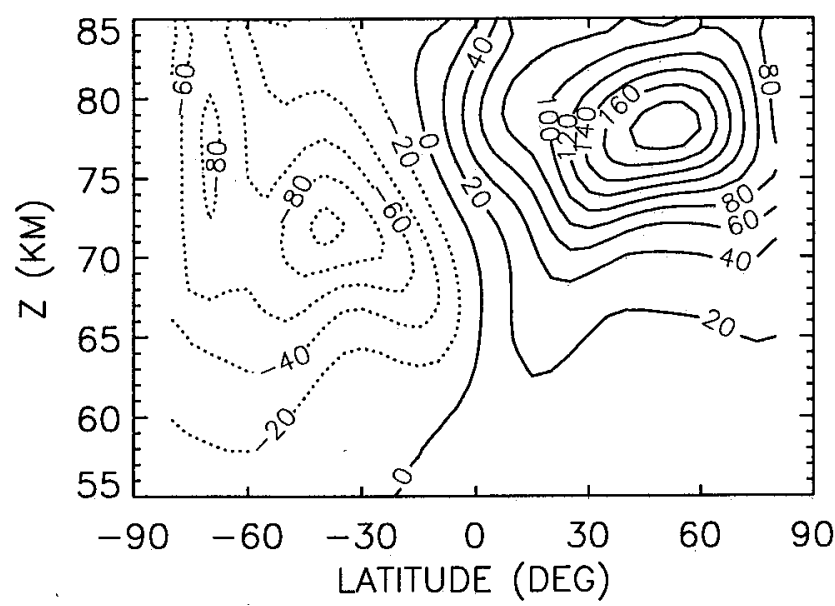

Figure 2. Gravity wave forcing for June $\left(\mathrm{m} \mathrm{s}^{-1} \mathrm{~d}^{-1}\right)$ in the mesosphere using the linear model with saturation, the Alexander [1996] (A96) model described in the text. Background winds and temperatures were specified from June CIRA. The magnitude of the forcing at these altitudes is used to calibrate the efficiency factor in these calculations. The December solstice case (not shown) looks similar with the latitude axis reversed. mesophere is a common feature of these model calculations. Summertime drag is generally a factor of 2 larger than winter, despite the absence of seasonal asymmetries in the assumed sources. A seasonal asymmetry of this magnitude is also suggested by observations [Fritts and Vincent, 1987; Fritts and Yuan, 1989].

More complex spectra with up to 9000 spectral elements were also tested and gave very similar results if a smaller efficiency factor is chosen. Source altitudes at 0 and $15 \mathrm{~km}$ were also tested. Wave amplitudes must then be adjusted to account for the change in density with source height, and the results in the lowermost stratosphere can be affected, but above $\sim 25 \mathrm{~km}$, these different source heights do not greatly affect the results. Whether the spectrum is specified to be isotropic in groundrelative frequency or intrinsic frequency results in more or less summer/winter asymmetry in the mesosphere forcing and can again affect the lowermost stratosphere, but this is relatively unimportant to the results in the middle and upper stratosphere. Characterization of gravity wave spectral properties for nonstationary sources is currently an area of active research, and developments in this area can be incorporated into the present model in future work.

The choice of a white (flat) momentum flux spectrum might at first seem odd, but we note that such a spectrum will still be decidedly red (emphasizing the lower frequencies) in zonal velocity or temperature variance. It should also be noted that observations do not as yet directly constrain the momentum flux spectrum at source levels. Bergman and Salby [1994] infer a momentum flux spectrum $\propto \omega^{-1.4}$ for long-period, inertiagravity waves by using global cloud variability as a proxy for convective wave sources. Some effects of spectra like these that emphasize the lower frequencies will be discussed at the end of this section.

For the purpose of comparison to the constraining evidence in the stratosphere (Figure 1), we use NMC derived winds shown in Figure 3. These are 4-year averages and appear quite similar to the CIRA stratospheric winds in the extratropics. The stratospheric results for both June and December are shown in Figures $4 \mathrm{a}$ and $4 \mathrm{~b}$. The summer hemisphere results are broadly similar to the residual forcing estimates in Figure 1. Specifically, the pressure level where the forcing changes sign is near $1 \mathrm{hPa}$ near the stratopause. The source amplitude was chosen to select this pressure level. Magnitudes peak at $0.5 \mathrm{~m} \mathrm{~s}^{-1} \mathrm{~d}^{-1}$ near $45-50 \mathrm{~km}$ but are much smaller than the observationally derived results (Figure 1) in the lower stratosphere. Downward mass fluxes integrated over the summer extratropics on the $75-\mathrm{hPa}$ surface are given in the first column of Table 1 (labeled A96a). These fluxes are estimated with the downward control principle using only this gravity wave component of the zonal force. Downward fluxes of magnitude $1 \times 10^{9} \mathrm{~kg} \mathrm{~s}^{-1}$ (along with the associated adiabatic warming) are required to explain the southern summer temperatures in the lower stratosphere reported by Rosenlof [1996].

The results in Figure 4 are sensitive to the amplitudes of the waves at the source level. To demonstrate this, the spectral amplitudes were uniformly multiplied by factors of 10 and 100 , and the results with June winds are shown in Figures $5 \mathrm{a}$ and $5 \mathrm{~b}$, respectively. Efficiency factors for these cases are $2 \times 10^{-4}$ and $1.8 \times 10^{-4}$, respectively. As the source amplitudes increase, the influence of the mesospheric drag gradually descends into the stratosphere, until in Figure $5 \mathrm{~b}$, the sense of the gravity wave forcing is actually reversed from that in Figure $4 \mathrm{~b}$ above $20 \mathrm{~km}$. Integrated momentum fluxes for Figures $5 \mathrm{a}$ and $5 \mathrm{~b}$ are 

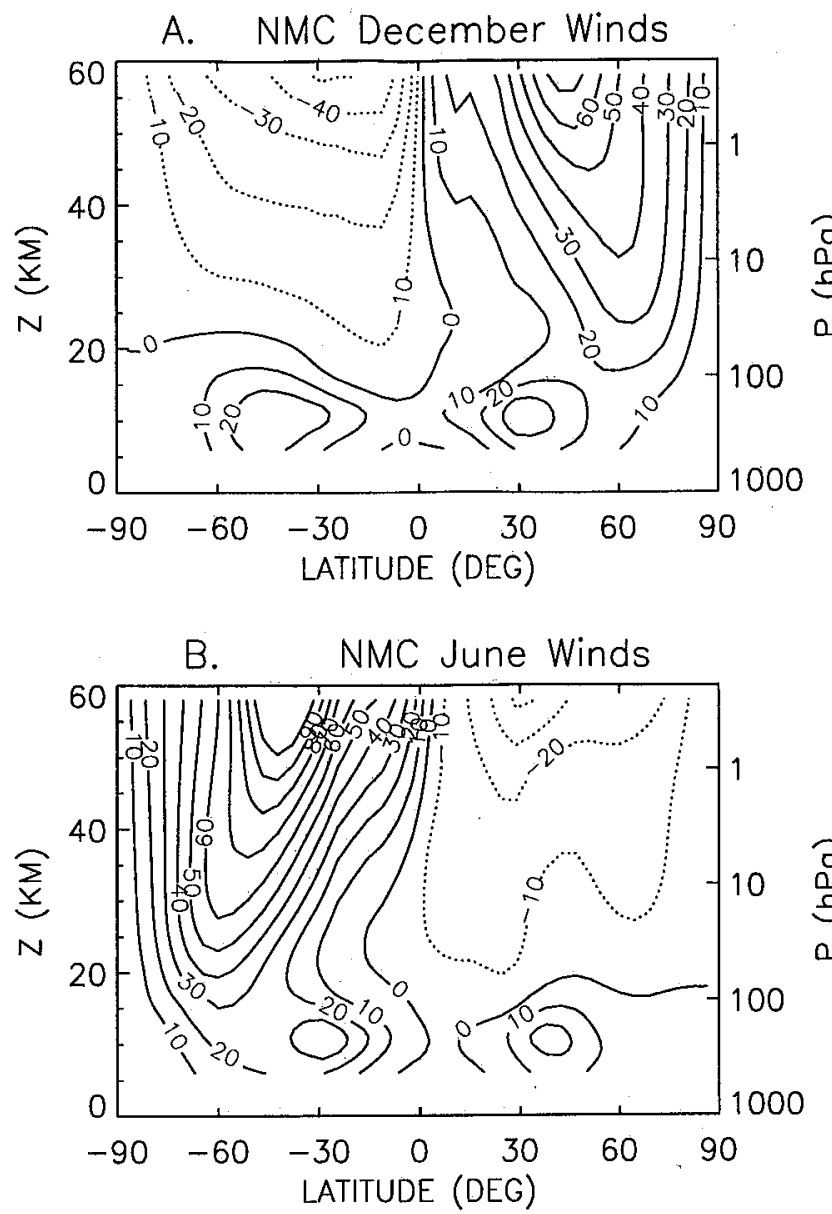

Figure 3. Stratospheric (a) December and (b) June zonal winds from a 1991-1994 average of NMC data. These 4-year averaged data are used to specify the background state for the gravity wave forcing estimates in Figures 4 through 7.

$\pm 18.0 \times 10^{-3}$ and $\pm 162 \times 10^{-3} \mathrm{~kg} \mathrm{~m}^{-1} \mathrm{~s}^{-2}$, respectively. The source flux must increase to give the same force in the mesosphere because a larger fraction of the flux is deposited in the stratosphere. The magnitude of the stratospheric force does not increase proportionately because as amplitudes increase, waves of both positive and negative intrinsic phase speed are breaking in the stratosphere, canceling each other's effect to large degree.

Changes to the shape of the source spectrum can also lead to changes in momentum flux deposition with altitude. When the spectrum is very red in frequency or phase speed, the lowfrequency waves break in the lower stratosphere, giving larger forcing there than in Figure 4. The high-frequency waves in this case do not break until much higher altitudes. The result (not shown) is a forcing distribution more similar to Figure $5 b$, but with weaker forcing in the middle stratosphere.

To obtain a forcing distribution that more resembles the observations (Figure 1), a momentum flux spectrum that peaks at intrinsic phase speeds of $\pm 20 \mathrm{~m} \mathrm{~s}^{-1}$ was selected. This shape is similar to the momentum flux spectrum of gravity waves forced by the tropical squall line simulations in Alexander and Holton [1996]. The integrated momentum flux in the source spectrum for this case is $\pm 15.5 \times 10^{-3} \mathrm{~kg} \mathrm{~m}^{-1} \mathrm{~s}^{-2}$, and vertical velocity amplitudes are all $\leq 2 \mathrm{~m} \mathrm{~s}^{-1}$ at the source. Figures $6 a$ and $6 \mathrm{~b}$ show the results for December and June, respectively.
The force is now $0.5-1 \mathrm{~m} \mathrm{~s}^{-1} \mathrm{~d}^{-1}$ over most of the summer stratosphere. The downward mass fluxes associated with Figure 6 are given in the second column of Table 1 (labeled A96b). These are 4-5 times larger than the fluxes in the A96a column because the force magnitude is much larger in the lower stratosphere in Figure 6 than in Figure 4. The asymmetry in the fluxes between northern and southern summer is also enhanced, more in line with the temperature asymmetries observed by Rosenlof [1996].

Although the results in Figure 6 agree much better with the observations in Figure 1, it is premature to conclude that the gravity wave phase speed spectrum peaks at $\pm 20 \mathrm{~m} \mathrm{~s}^{-1}$ or that the gravity wave momentum flux is some particular value. The maps in Figure 1 are still rather uncertain and do not really warrant detailed tuning of the gravity wave parameters in this model to match them. Instead, Figure 6 is intended to demonstrate the range of allowed forcing distributions using the A96 model and isotropic, globally uniform gravity wave sources.
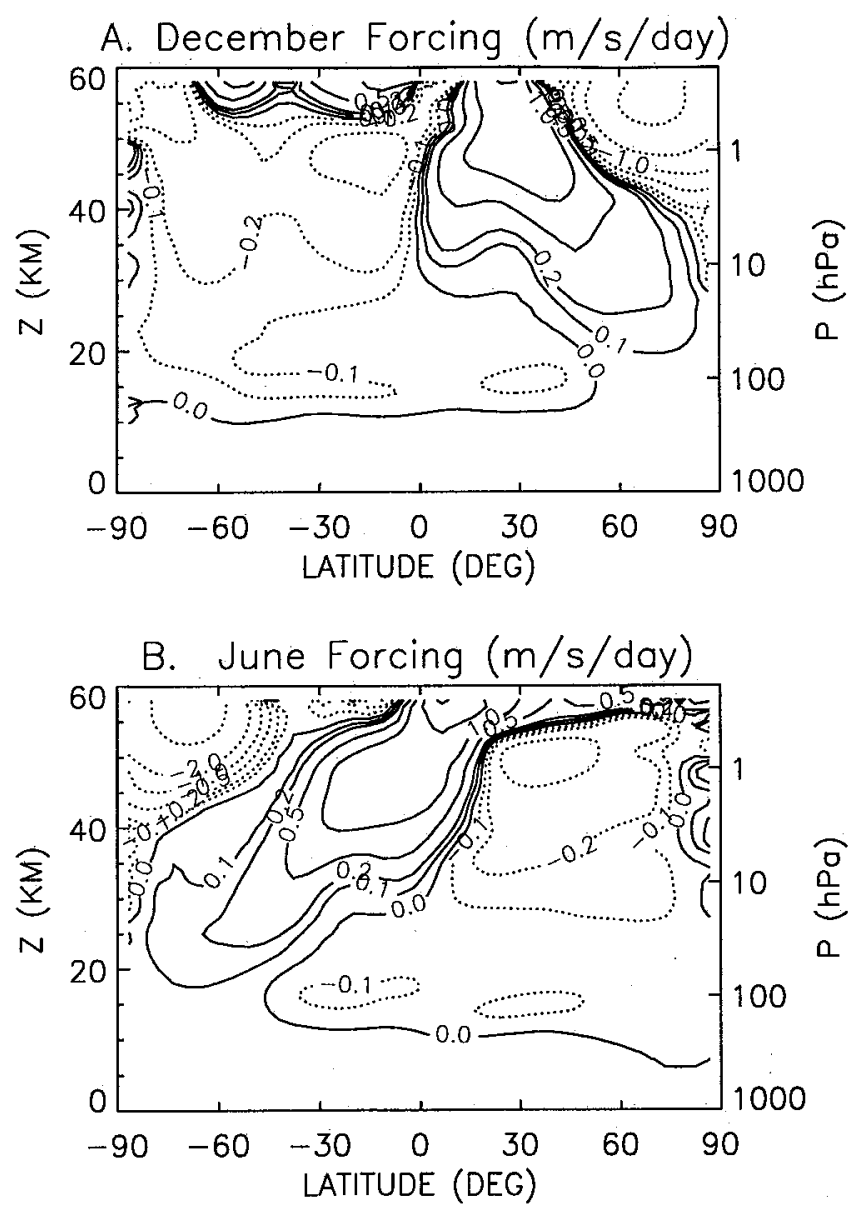

Figure 4. Gravity wave forcing estimates for (a) December and (b) June from the A96 model using simple assumptions about the nonstationary gravity wave source spectrum applied uniformly at all latitudes: The gravity wave momentum flux is constant for each wave in the spectrum. Semilog contours are chosen as follows: $0,0.1,0.2,0.5,1$, and $5 \mathrm{~m} \mathrm{~s}^{-1} \mathrm{~d}^{-1}$. Dashed contours represent negative values. The forcing distributions in the summer seasons are similar to those in the small-scale residual maps in Figure 1. The negative summer forcing above $\sim 20 \mathrm{~km}$ in the stratosphere represents an accelerative force that drives a downward component of the mass flux in the summer lower stratosphere (Table 1, A96a). 
Table 1. Gravity Wave Component of the Summer Downward Mass Flux at $75 \mathrm{hPa}$ Poleward of $35^{\circ}$

Summer Downward Flux, $10^{8} \mathrm{~kg} \mathrm{~s}^{-1}$

Hemisphere

A96a A96b FL93

L81

\begin{tabular}{lllll}
\hline Northern & +5.0 & +20.0 & -9.8 & -5.6 \\
Southern & +6.1 & +28.6 & -12.1 & -1.8
\end{tabular}

A96 refers to Alexander [1996], with A96a derived from the forcing distributions in Figure 4 and A96b from those in Figure 6. FL93 is Fritts and Lu [1993]. L81 is based on Lindzen [1981].

Anisotropies and geographical and seasonal variations in gravity wave source properties have not been tested here but could further expand the range of attainable forcing distributions in the stratosphere.
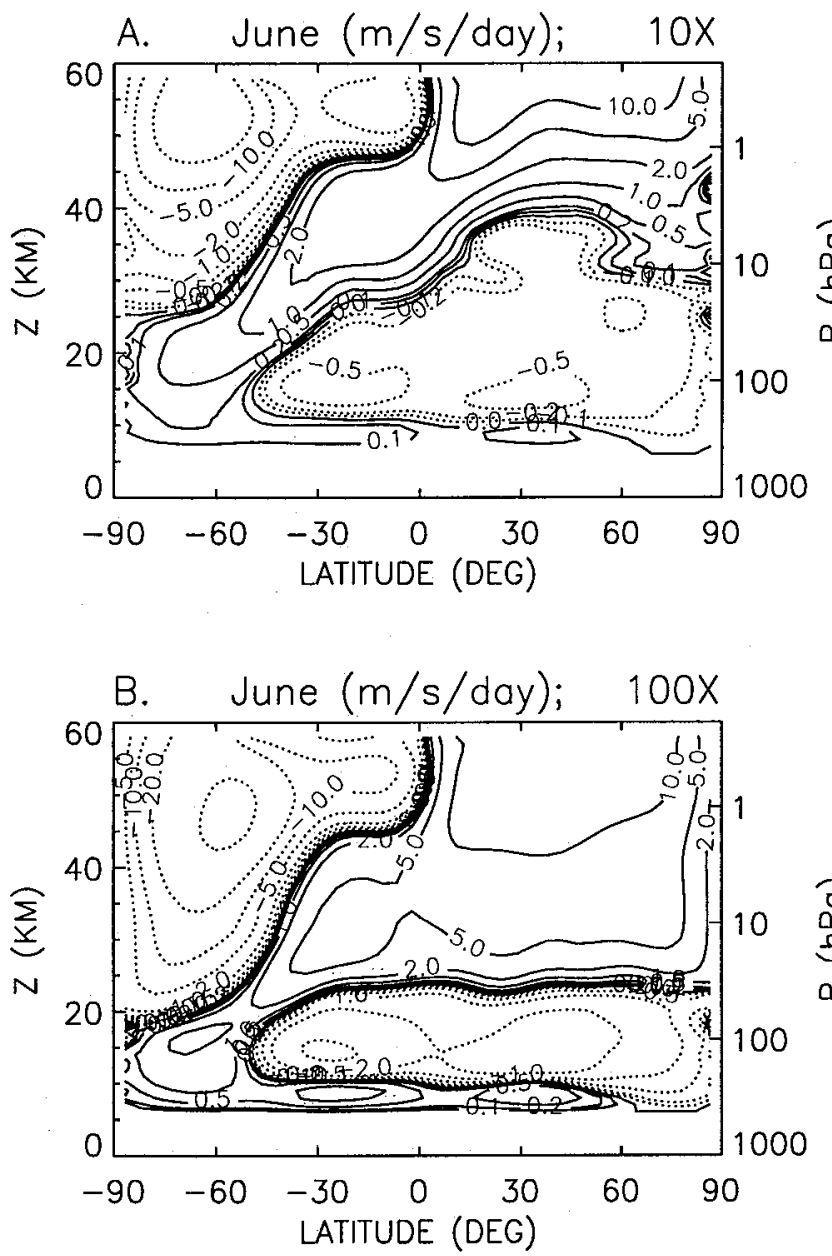

Figure 5. Gravity wave forcing estimates from the A96 model using amplified versions of the source spectrum used to derive Figure $4 \mathrm{~b}$ (June case). Contours are the same as in Figure 4. The source amplification factors are (a) 10 and (b) 100 . Efficiency factors were simultaneously reduced (see text). The $100 \mathrm{x}$ case produces a gravity wave force opposite in sign to that in Figure 4 at extratropical latitudes.

\subsection{Fritts and $L u$ [1993] Parameterization (FL93)}

Fritts and $L u$ [1993] (hereinafter referred to as FL93) describe a spectral parameterization of gravity wave forcing based on the theory of gravity wave saturation and constrained by empirical spectral properties of waves in the middle and upper atmosphere. The results of this parameterization with the same NMC backround state for June and December are shown in Figures 7a and $7 \mathrm{~b}$, respectively. The nominal parameters described by Fritts and $L u$ [1993] have been used here $\left(c *_{\mathrm{i}}= \pm 5 \mathrm{~m} \mathrm{~s}^{-1}, \alpha=0.2\right.$, $\left.E_{0} \propto \exp [z /(2.3 H)]\right)$ where $c *_{\mathrm{i}}$ are the characteristic source level phase speeds, $\alpha$ is the anisotropy factor, and $E_{0}$ the total wave energy profile). The sense of the force in the summer extratropics is nearly the reverse of that in Figures 4 and 6 and of the summer hemispheres in the observations (Figure 1). The extratropical downward mass flux in the summer hemispheres for these forcing estimates is listed in the third column of Table 1 (labeled FL93). As expected, the flux is opposite in sign to the A96 calculations. Instead, the stratospheric drag from FL93 looks very similar to the large-amplitude calculation in Figure $5 \mathrm{~b}$, but with smaller magnitude.
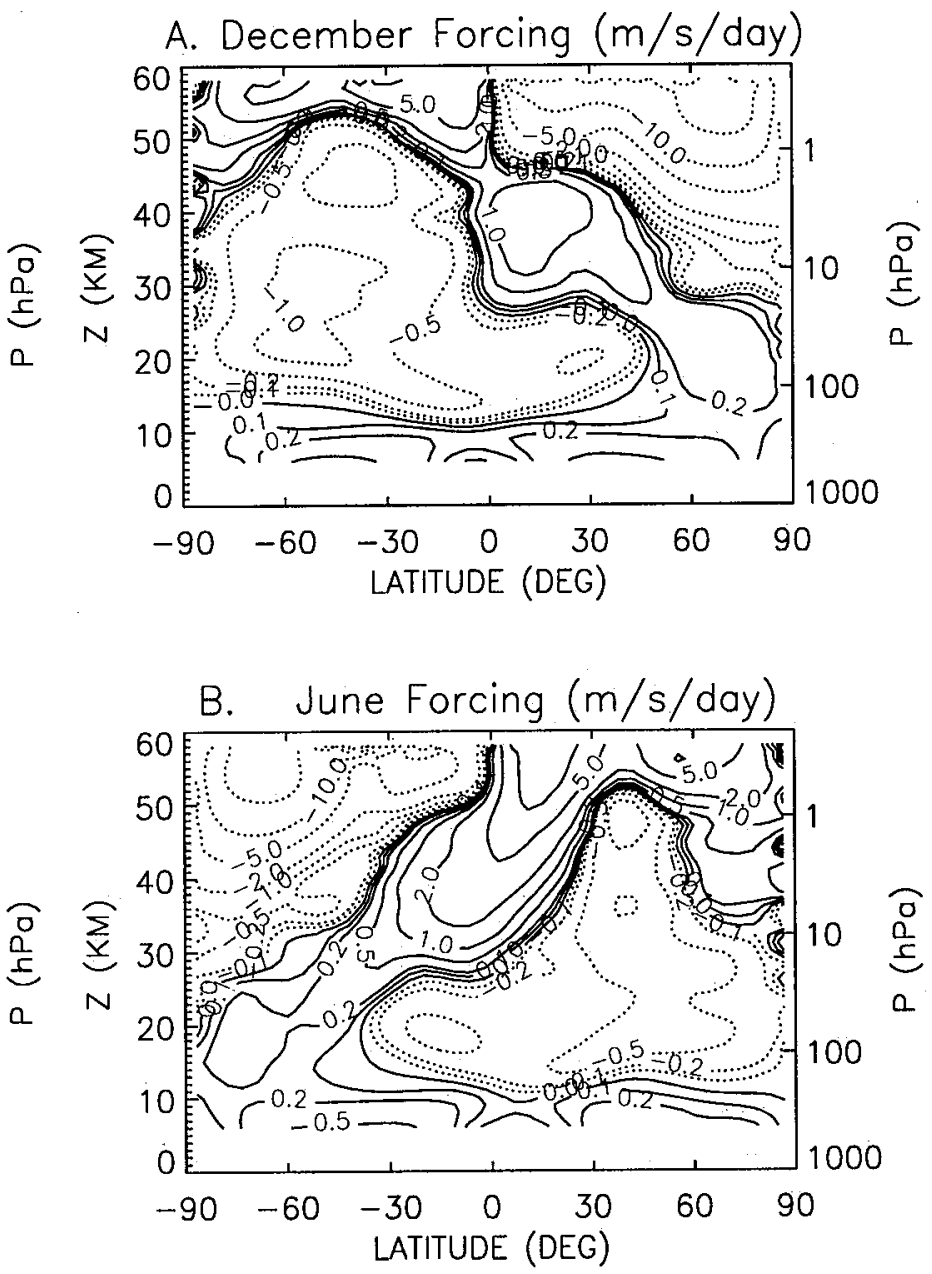

Figure 6. Gravity wave forcing estimates for (a) December and (b) June from the A96 model using an isotropic momentum flux source spectrum that peaks at $\pm 20 \mathrm{~m} \mathrm{~s}^{-1}$ phase speed. Contours are the same as in Figure 4. This choice of source spectrum gives a forcing distribution more similar in magnitude to the observationally derived estimates in Figure 1. The corresponding downward mass flux estimates are given in Table 1 (A96b). 

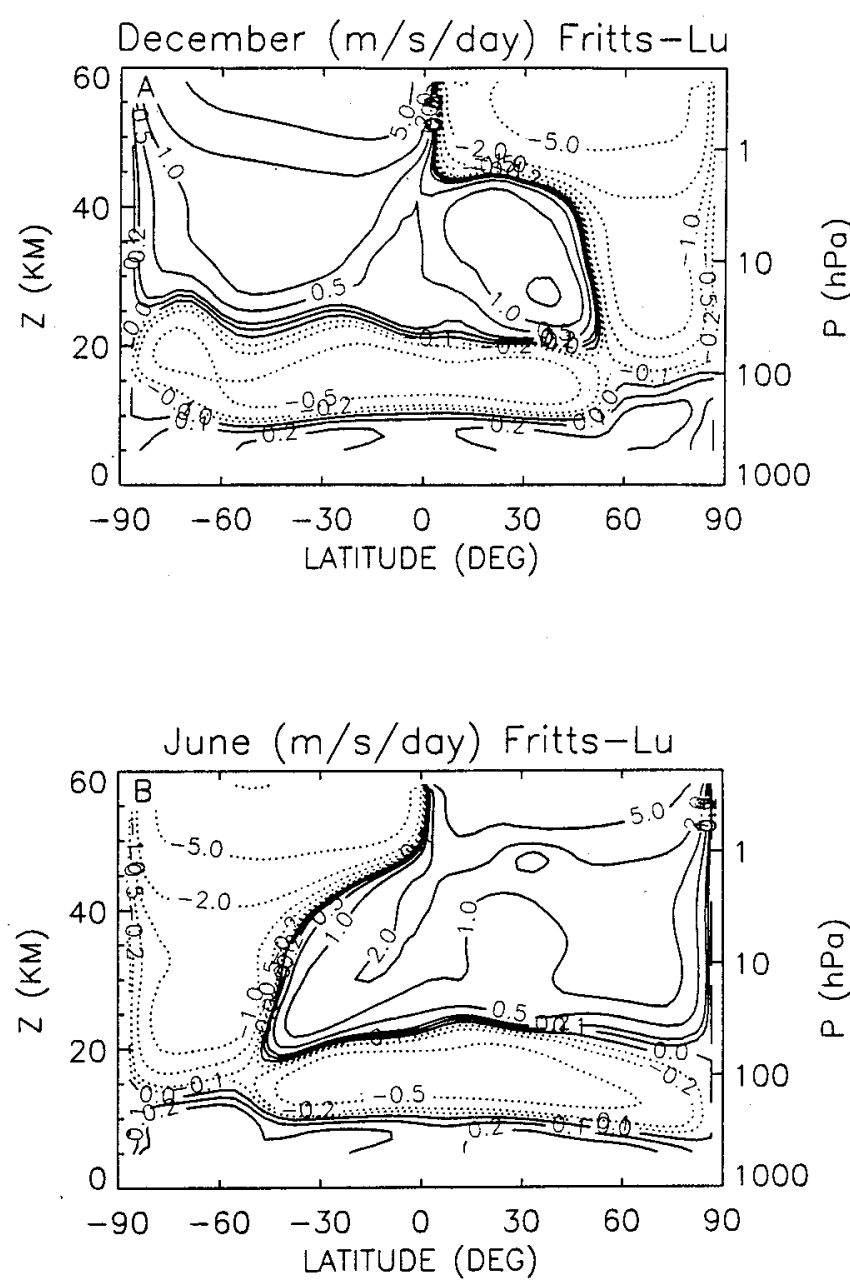

Figure 7. Gravity wave forcing estimates for (a) December and (b) June from the Fritts and $L u$ [1993] parameterization. Contours are the same as in Figure 4. The sign of the forcing in the extratropics is reversed from that in Figures 4 and 6 . This component of the forcing would generate mass fluxes in the lower stratosphere opposite in sign to the A96 model (Table 1, FL93).

Changing the characteristic phase speed at the source level $c *$ to much smaller values serves to decrease the magnitude of the gravity wave forcing but has no effect on the patterns of the force distribution or its sign. The value of $\alpha$, the anisotropy limit in FL93, likewise has no effect. Smaller-energy growth-scale heights, less than $2.3 \mathrm{H}$, do have some effect, although too small to reproduce distributions more like those in Figures 1, 4, and 6.

The disagreement is likely related to the assumed separability and shape of the gravity wave spectrum in the parameterization. Both eastward and westward propagating components of the spectrum are assumed to have the same empirically based "saturated" shape (described by the Desaubies spectrum). Relative energies in the east/west components are dependent only on the mean wind shear. This fixes the phase relationship between the gravity wave driven force profile and the mean wind (for a given set of background conditions).

In the A96 model, on the other hand (and in the Lindzen parameterization), the phase relationship between the force and the mean wind varies with the wave source amplitudes. The descent of the mesospheric drag with increasing source strength shown in Figure 5 can be understood as a progressive increase in the vertical distance between wave breaking and critical levels as a function of altitude. Waves break close to their critical levels in the lower stratosphere and break progressively farther below them as the spectrum progresses into the mesosphere. Critical level filtering of the wave spectrum also plays a role; however, if that were the only process at work, the phase relationship (in $z$ ) between the wind and the gravity wave force would be fixed, not dependent on the wave amplitudes as observed here.

The effect is illustrated in Figure 8a. The solid line shows the mean wind profile at $47^{\circ} \mathrm{S}$ latitude in December. This line can also be thought of as representing a plot of wave phase speed versus critical level altitude. For spectral source amplitudes such as those used in Figure 4, the waves do not break until fairly close to their critical levels in the stratosphere (dotted line). The spectrum is not separable as assumed by Fritts and $\mathrm{Lu}$ [1993]. Instead, only the low intrinsic frequency waves are saturated. Conversely, using a source spectrum with 100x larger amplitudes (as in Figure 5b), most of the waves break in the lower stratosphere (dashed line) so that most of the spectrum is now saturated throughout the stratosphere and looks more like the spectrum assumed in the parameterization.

The only partly saturated phase speed spectrum for the lowamplitude case (dotted line in Figure 8a) is not separable, yet still appears saturated when viewed as a spectrum versus vertical wavenumber only. Figure $8 \mathrm{~b}$ shows the one-dimensional power spectrum of the horizontal velocity versus vertical wavenumber $m$ for the low-amplitude case in the altitude region between 30 and $40 \mathrm{~km}$. (Note that an analogous, but higher-resolution source spectrum with 900 spectral elements was necessary to produce Figure $8 \mathrm{~b}$.) The dashed line in Figure $8 \mathrm{~b}$ shows the theoretical saturated spectrum $N^{2} /\left(7.5 \mathrm{~m}^{3}\right)$ [Fritts and VanZandt, 1993]. The vertical wavenumber spectrum appears saturated because the largest-amplitude waves are saturated and dominate the spectrum. However, only the low intrinsic frequency waves are saturated at these altitudes, so the two-dimensional $(\omega, m)$ spectrum would not appear saturated at all frequencies, and the spectrum is not separable.

The empirical evidence on which the Fritts and $\mathrm{Lu}$ [1993] parameterization is based is sorely lacking in the middle and upper stratosphere. This region is nearly transparent to traditional radar techniques and out of reach of routine radiosonde observations, so no description of the climatology of gravity waves at these altitudes had been available. Recently, Eckermann et al. [1995] describe an analysis of long-term rocket soundings covering this altitude region, and the VHF radar [Maekawa et al., 1993] and satellite observations [Wu and Waters, 1996] show promise for constraining a climatology of gravity wave variance in the upper stratosphere. The constraints on the gravity-wave driven force developed here and by Rosenlof [1996] are the first, to our knowledge, applicable to the middle and upper stratosphere extratropics during the important summer seasons and should serve as a guide in future parameterization implementation and development.

\subsection{Lindzen [1981] Parameterization}

Figure 9 shows the gravity wave forcing resulting from the Lindzen [1981] parameterization, with the modifications suggested by Holton [1982] and the same input spectrum described for Figure 4. An efficiency factor of $10^{-4}$ was applied to calibrate the mesospheric forcing as described in section 3.1. The stratospheric gravity wave forcing distributions in Figure 9 


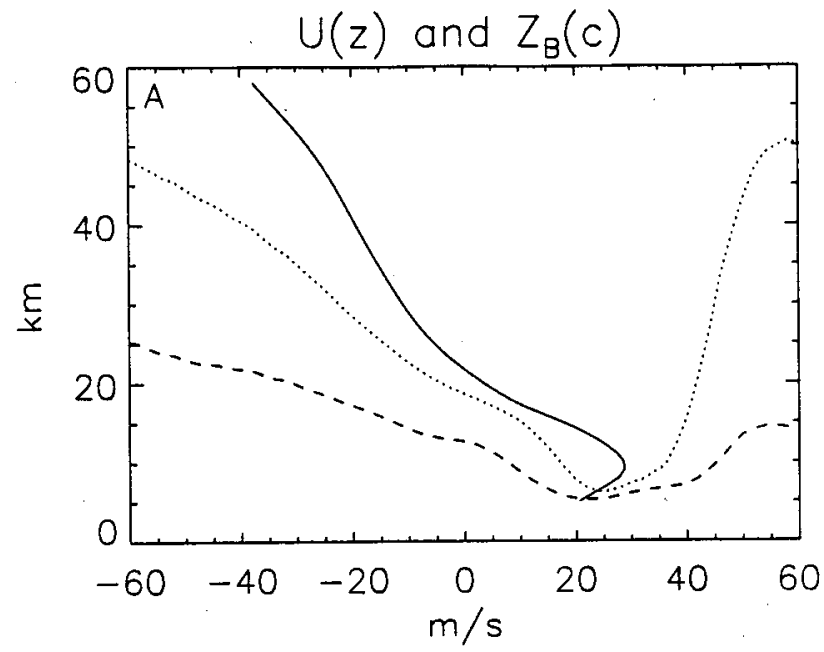

breaking and critical level. This leads to a much greater gravity wave forcing than the A96 model, which includes the amplitudereducing effect of the background shear in these cases. Lindzen's [1981] original parameterization can actually violate conservation of energy if the shear reversal is strong in order to maintain this adiabatic lapse rate. In these cases, an unphysical negative eddy diffusion coefficient would be predicted. Forbes et al. [1991] noticed this in their study of gravity wave interactions with the tides, adding a condition to turn off the gravity wave forcing in these regions. McFarlane's [1987] scheme for stationary waves includes a condition on the background shear that also avoids such nonphysical results. In many applications of the Lindzen [1981] scheme, no such condition is specified, so it is unclear how such situations were treated [e.g., Miyahara and Forbes, 1991, Brasseur et al., 1990; Huang and Smith, 1995].

The extratropical downward mass fluxes at the 75-hPa level associated with these forcing estimates are given in the fourth column of Table 1 (labeled L81). The mass fluxes are intermediate between the A96a and FL93 results as might be expected from the forcing distributions. These flux estimates are sensitive to the forcing distribution above $75 \mathrm{hPa}$. The results of Lindzen's

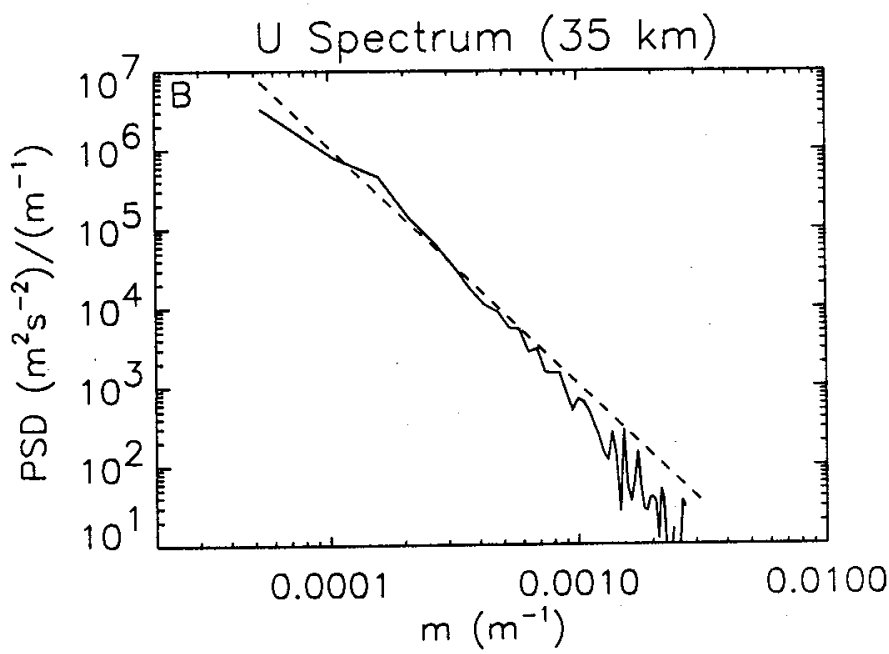
[1981] parameterization can be made to look more like the A96

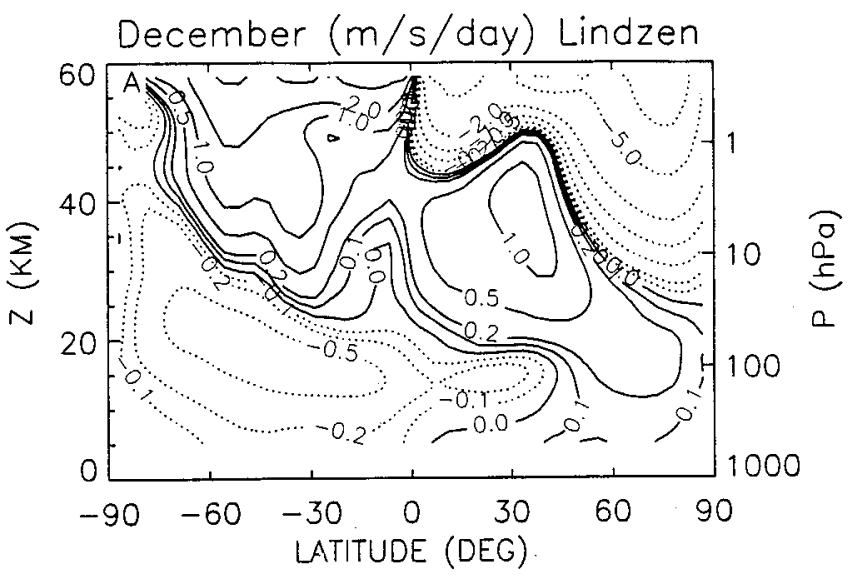

Figure 8. (a) Zonal mean wind profile (solid line) at $47^{\circ} \mathrm{S}$ latitude and profiles of breaking level $Z_{B}$ as a function of phase speed $c$ for two different source spectrum amplitudes. The dotted line shows $Z_{B}(c)$ for the nominal spectrum used to produce Figure $4 \mathrm{~b}$. The dashed line shows $Z_{B}(c)$ for the high-amplitude case, with amplitudes 100 times larger, the source spectrum used to produce Figure $5 \mathrm{~b}$. These breaking levels represent an average over all frequency/horizontal wavenumber pairs with phase speed $c$. (b) Power spectrum of horizontal velocity perturbations versus vertical wavenumber (solid line) for the low amplitude source spectrum case in Figure $8 \mathrm{a}$. The spectrum represents an average over alitudes of $30-40 \mathrm{~km}$. The dashed line shows the theoretical saturated spectrum (see text).

are intermediate between the A96 model results in Figure 4 and the Fritts and $L u$ [1993] parameterization (Figure 7).

The breaking levels in the Lindzen [1981] scheme are lower (for a given wave mode) than the A96 model, primarily because of the hydrostatic approximation made in Lindzen's model. Lindzen's model also does not treat wave reflection. Another difference arises above the breaking level in cases where the vertical shear of the zonal wind changes sign, as it does above the tropospheric jets. Lindzen's [1981] scheme assumes the local wave-plus-mean lapse rate remains adiabatic between the

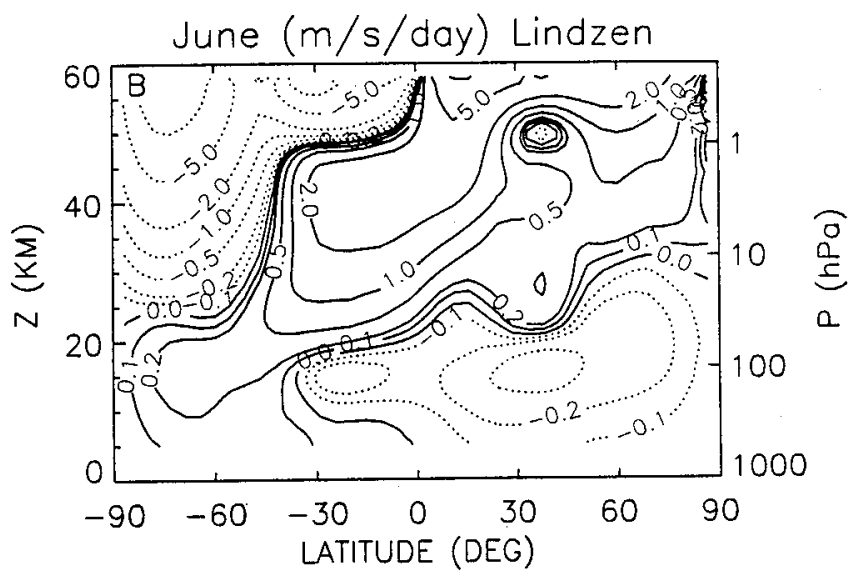

Figure 9. Gravity wave forcing estimates for (a) December and (b) June from the Lindzen [1981] parameterization. Contours are the same as in Figure 4. These are intermediate between the A96 (Figure 4) and Fritts and Lu [1993] (Figure 7) results. Lower stratospheric mass fluxes associated with these forcing estimates (Table 1, L81) are also intermediate in value. 
model if smaller source amplitudes and lower integrated momentum fluxes are specified to compensate for the lower breaking level predictions and lack of wave reflection.

\section{Discussion and Summary}

Zonal mean summertime temperatures in the southern hemisphere lower stratosphere are much warmer than would be expected from an analysis using the radiative forcing and largescale momentum sources only [Rosenlof, 1996]. A small-scale forcing is implied (due to waves not resolved in the NMC and UKMO data) that is an accelerative force throughout most of the summertime stratosphere between the 100- and 1-hPa levels (Figure 1). This is a westward force in the summer seasons. The small-scale forcing affects a summertime lower stratosphere temperature asymmetry between southern and northern hemispheres of $2.5-5^{\circ} \mathrm{K}$ [Rosenlof, 1996] and thus may be relevant to climate.

This small-scale accelerative force can be explained via nonstationary gravity wave interactions with the zonal mean wind if the wave amplitudes are such that the waves break at altitudes closer to their critical levels than has been assumed in many previous applications of the Lindzen [1981] parameterization. Many previous model applications of stratospheric gravity wave forcing have applied a decelerative zonal force throughout most of the extratropical middle and upper stratosphere, although such studies generally focused more on the mesosphere. Both stationary gravity wave drag and Rayleigh friction parameterizations produce decelerative zonal forces by definition.

It is widely accepted that gravity waves dominate the forcing in the mesosphere. There the zonal force opposes the zonal wind and drives a meridional circulation that warms the winter extratropics and cools in summer. In the middle and upper stratosphere, nonstationary gravity waves are here inferred to provide an accelerative zonal force which would give a tendency for downwelling in the summer extratropics and upwelling in winter. This small-scale, wave-driven component of the meridional circulation would weakly oppose the mean meridional circulation in winter, while enhancing it in summer.

Using a linear ray-tracing model with a saturation condition applied wherever wave amplitudes exceed convective instability limits, the transition from this accelerative force in the stratosphere to the decelerative gravity wave force known to exist in the mesosphere (Figure 2) is viewed as a gradual increase in the vertical distance between wave breaking and critical levels as a function of altitude coupled to critical level filtering effects on the spectrum. The breaking level evolution with height can be seen in Figure 8a. The differences in the zonal mean shear in the northern and southern summertime hemispheres (Figure 3) lead naturally to a prediction of somewhat larger gravity wave forces in the southern summer stratosphere (Figures 4 and 6) and, correspondingly, slightly larger downward mass fluxes (Table 1) and higher temperatures in the lower stratosphere. The seasonal differences in Table 1 arise with no differences in the gravity wave momentum flux at the source level. The lower stratospheric summer temperatures reported by Rosenlof [1996] suggest an even larger summertime asymmetry, which could imply either larger gravity wave momentum fluxes in southern summer than in the north or distinct differences in the shape or anisotropy of the momentum flux spectrum between the hemispheres.

The stratospheric forcing is very sensitive to the amplitudes of the waves at the source, which are directly related to the breaking levels of the waves. Much larger amplitude waves (with lower efficiency factors) can produce very similar mesospheric drag to that shown in Figure 2 while simultaneously completely reversing the sign of the gravity wave forcing in the stratosphere (Figure 5).

The conclusion that the forcing in the summer stratosphere must be accelerative thus imposes limits on gravity wave amplitudes at the source level, vertical velocities all $<2 \mathrm{~m} \mathrm{~s}^{-1}$ at $6 \mathrm{~km}$ for a wide range of different source spectrum shapes. (Note that mean amplitudes are $0.5-0.9 \mathrm{~m} \mathrm{~s}^{-1}$ ). The magnitude of the forcing in the mesosphere further places limits on the total momentum flux the gravity waves carry at the source level in this model. These two limits provide rather powerful constraints on the stratospheric forcing magnitude generated by the A96 model. The results do not provide any strong constraints on gravity wave momentum fluxes at source levels in nature because uncertainties in the spectral properties of the wave sources can accommodate a wide range of zonal momentum fluxes.

Observations suggest that in the winter seasons, the gravity wave forcing is only a small fraction (10-20\%) of large-scale wave forcing in the stratosphere. The small-scale forcing in Figure 1 for the winter seasons appears quite noisy because of the importance of the large-scale EP-flux divergence term there, which has large uncertainty. Thus Figure 1 is not likely to provide any reliable constraints on the small-scale forcing in winter. However, the model results in Figures 4 and 6 should provide some estimate of the nonstationary component of the gravity wave forcing in winter seasons. It, too, is predicted to be an accelerative force at extratropical latitudes in the middle stratosphere. Stationary orographic waves can, however, penetrate to much higher altitudes in the stratosphere in winter seasons because of the lack of critical levels in the zonal mean wind, and their decelerative effects might weaken considerably the strength of the winter forcing in Figures 4 and 6 or even reverse its sign.

It is also worth noting that the nonstationary wave forcing above the tropospheric jets in Figures 4 and 6 is decelerative and so will work in concert with any stationary wave drag at these levels. Thus global circulation models which have tuned their topographic wave drag to decelerate the tropospheric jets may need to tune down the strength of that drag if nonstationary wave effects are subsequently included.

Acknowledgments. The authors acknowledge Bill Randel for providing the NMC EP-flux divergence calculations that went into producing Figure 1. We also thank Jim Holton, Dave Fritts, Tim Dunkerton, Rolando Garcia, and two anonymous reviewers for their comments on this manuscript. This work was supported by the Physical Meteorology Program of the National Science Foundation, ATM-9322480, and the National Aeronautics and Space Administration, NASA grant NAG11803. Support for K.H.R. came from the National Oceanic and Atmospheric Administration's Aeronomy Laboratory.

\section{References}

Alexander, M. J., A simulated spectrum of convectively generated gravity waves: Propagation from the tropopause to the mesopause and effects on the middle atmosphere, J. Geophys. Res., 101, 1571-1588, 1996.

Alexander, M. J., and J. R. Holton, A model study of zonal forcing in the equatorial stratosphere by convectively induced gravity waves, J. Atmos. Sci., accepted, 1996.

Alexander, M. J., D. R. Durran, and J. R. Holton, The gravity wave response above deep convection in a squall line simulation, J. Atmos. Sci., 52, 2212-2226, 1995.

Andrews, D. G., J. R. Holton, and C. B. Leovy, Middle Atmosphere Dynamics, 489 pp., Academic P., San Diego, California, 1987.

Bacmeister, J. T., Mountain-wave drag in the stratosphere and meso- 
sphere inferred from observed winds and a simple mountain-wave parameterization scheme, J. Atmos. Sci., 50, 377-399, 1993.

Bergman, J. W., and M. L. Salby, Equatorial wave activity derived from fluctuations in observed convection, J. Atmos. Sci., 51, 3791-3806, 1994.

Brasseur, G., M. H. Hitchman, S. Walters, M. Dymek, E. Falise, and $M$. Pirre, An interactive chemical dynamical radiative twodimensional model of the middle atmosphere, J. Geophys. Res., 95, $5639-5655,1990$.

Dunkerton, T. J., Theory of the mesopause semiannual oscillation, J. Atmos. Sci., 39, 2681-2690, 1982.

Dunkerton, T. J., Nonlinear Hadley circulation driven by asymmetric differential heating, J. Atmos. Sci., 46, 956-974, 1989.

Dunkerton, T. J., The role of gravity waves in the quasi-biennial oscillation, J. Geophys. Res., in press, 1996.

Eckermann, S. D., I. Hirota, and W. K. Hocking, Gravity wave and equatorial wave morphology of the stratosphere derived from longterm rocket soundings, Q. J. R. Meteorol. Soc.; 121, 149-186, 1995.

Edmon, H. J., Jr., B. J. Hoskins, and M. E. McIntyre, Eliassen-Palm cross sections for the troposhere, J. Atmos. Sci., 37, 2600-2616, 1980.

Fleming, E. L., S. Chandra, J. J. Barnett, and M. Corney, Zonal mean temperature, pressure, zonal wind and geopotential height as functions of latitude, Adv. Space Res., 10, (12)11-(12)59, 1990.

Forbes, J. M., J. Gu, and S. Miyahara, On the interactions between gravity waves and the diurnal propagating tide, Planet. Space Sci., 39, 1249-1257, 1991.

Fritts, D. C., and W. Lu, Spectral estimates of gravity wave energy and momentum fluxes, II: Parameterization of wave forcing and variability, J. Atmos. Sci., 50, 3695-3713, 1993.

Fritts, D. C., and T. E. VanZandt, Spectral estimates of gravity wave energy and momentum fluxes, I: Energy dissipation, acceleration, and constraints, J. Atmos. Sci., 50, 3685-3694, 1993.

Fritts, D. C., and R. A. Vincent, Mesospheric momentum flux studies at Adelaide, Australia: Observations and a gravity wave-tidal interaction model, J. Atmos. Sci., 44, 605-619, 1987.

Fritts, D. C., and L. Yuan, Measurement of momentum fluxes near the summer mesopause at Poker Flat, Alaska, J. Atmos. Sci., 46, 2569-2579, 1989.

Garcia, R. R., and B. A. Boville, "Downward control" of the mean meridional circulation and temperature distribution of the polar winter stratosphere, J. Atmos. Sci., 51, 2238-2245, 1994.

Garcia, R. R., and S. Solomon, The effect of breaking gravity waves on the dynamics and chemical composition of the mesosphere and lower thermosphere, J. Geophys. Res., 90, 3850-3868, 1985.

Hamilton, K., Diagnostic study of the momentum balance in the northern hemisphere winter stratosphere, Mon. Weather Rev., I11, 1434-1441, 1983.

Hamilton, K., and J. D. Mahlman, General circulation model simulation of the semiannual oscillation of the tropical middle atmosphere, J. Atmos. Sci., 45, 3212-3235, 1988.

Hartmann, D. L., The dynamical climatology of the stratosphere in the southern hemisphere during late winter 1973, J. Atmos. Sci., 33, $1789-1802,1976$.

Haynes, P. H., C. J. Marks, M. E. McIntyre, T. G. Shepherd, and K. P. Shine, On the "downward control" of extratropical diabatic circulations by eddy-induced mean zonal forces, J. Atmos. Sci., 48, 651-678, 1991.

Hitchman, M. H., J. C. Gille, C. D. Rodgers, and G. Brasseur, The separated polar winter stratopause: A gravity wave driven climatological feature, J. Atmos. Sci., 46, 410-422, 1989.

Holton, J. R., The role of gravity wave induced drag and diffusion in the momentum budget of the mesosphere, J. Atmos. Sci., 39, 791-799, 1982.
Holton, J. R., The influence of gravity wave breaking on the general circulation of the middle atmosphere, J. Atmos. Sci., 40, 2497-2507, 1983.

Huang, T. Y. W., and A. K. Smith, Dynamical and chemical feedback in a two-dimensional interactive model of the middle atmosphere, J. Geophys. Res., 100, 11,085-11,104, 1995.

Jackson, D. R., and L. J. Gray, Simulation of the semi-annual oscillation of the equatorial middle atmosphere using the Extended UGAMP General Circulation Model, Q. J. R. Meteorol. Soc., 120, 1559-1588, 1994.

Leovy, C., Simple models of thermally driven mesospheric circulation, J. Atmos. Sci., 21, 327-341, 1964.

Lindzen, R. S., Turbulence and stress owing to gravity wave and tidal breakdown, J. Geophys. Res., 86, 9707-9714, 1981.

Maekawa, Y., S. Fukao, M. Yamamoto, M. D. Yamanaka, T. Tsuda, S. Kato, and R. F. Woodman, First observation of the upper stratospheric vertical wind velocities using the Jicamarca VHF radar, Geophys. Res. Lett., 20, 2235-2238, 1993.

Marks, C. J., and S. D. Eckermann, A three-dimensional nonhydrostatic ray-tracing model for gravity waves: Formulation and preliminary results for the middle atmosphere, J. Atmos. Sci., 52, 1959-1984, 1995.

McFarlane, N. A., The effect of orographically excited gravity wave drag on the general circulation of the lower stratosphere and troposphere, J. Atmos. Sci., 44, 1775-1800, 1987.

Miyahara, S., and J.M. Forbes, Interactions between gravity waves and the diurnal tide in the mesosphere and lower thermosphere, J. Meteorol. Soc. Jpn., 69, 523-531, 1991.

Palmer, T. N., G. J. Shutts, and R. Swinbank, Alleviation of a systematic westerly bias in general circulation and numerical weather prediction models through an orographic gravity wave drag parameterization, Q. J. R. Meteorol. Soc., 112, 1001-10039, 1986.

Randel, W. J., Global Atmospheric Circulation Statistics, 1000-1 mb, 256 pp., Natl. Cent. for Atmos. Res., Boulder, Colo., 1992.

Rosenlof, K. H., Seasonal cycle of the residual mean meridional circulation in the stratosphere, J. Geophys. Res., 100, 5173-5191, 1995.

Rosenlof, K. H., Summer hemisphere differences in temperature and transport in the lower stratosphere, J. Geophys. Res., in press, 1996.

Shine, K., Sources and sinks of zonal momentum in the middle atmosphere diagnosed using the diabatic circulation, Q. J. R. Meteorol. Soc., 115, 265-292, 1989.

Smith, A. K., and L. V. Lyjak, An obseryational estimate of gravity wave drag from the momentum balance in the middle atmosphere, J. Geophys. Res., 90, 2233-2241, 1985.

Spencer, R. W., J.R. Christy, and N.C. Grody, Global atmospheric temperature monitoring with satellite microwave measurements: Method and results 1979-1984, J. Clim., 3, 1111-1128, 1990.

Wu, D. L., and J. W. Waters, Satellite observations of atmospheric gravity waves, Geophys. Res. Lett., in press, 1996.

M. J. Alexander, Department of Atmospheric Sciences, University of Washington, Box 351640, Seattle, WA 98195-1640.

(e-mail: alexand@atmos.washington.edu)

K. H. Rosenlof, Cooperative Institute for Research in Environmental Sciences, University of Colorado, NOAA, 325 Broadway R/E/AL6, Boulder, CO 80309-0216. (e-mail: krosenlof@atztec.al.bldrdoc.GOV)

(Received February 21, 1996; revised July 3, 1996; accepted July 3, 1996.) 